\title{
Characteristic Autonomic Nervous Activity of Institutionalized Elders with Dementia
}

\author{
Shoko Fuji1, Tetsuya Tanioka2*, Yuko Yasuhara², Miki Sato ${ }^{3}$, Ken Saito², \\ Marguerite J. Purnell4, Rozzano Locsin ${ }^{4}$, Toshiyuki Yasui ${ }^{2}$ \\ ${ }^{1}$ Graduate School of Health Sciences, Tokushima University, Tokushima, Japan \\ ${ }^{2}$ Divisions of Health Sciences, Institute of Biomedical Sciences, Tokushima University Graduate School, \\ Tokushima, Japan \\ ${ }^{3}$ Department of Nursing, Faculty of Nursing, Shikoku University, Tokushima, Japan \\ ${ }^{4}$ Christine E. Lynn College of Nursing, Florida Atlantic University, Boca Raton, Florida, USA \\ Email: *tanioka.tetsuya@tokushima-u.ac.jp
}

Received 24 October 2015; accepted 26 December 2015; published 29 December 2015

Copyright (C) 2016 by authors and Scientific Research Publishing Inc.

This work is licensed under the Creative Commons Attribution International License (CC BY).

http://creativecommons.org/licenses/by/4.0/

(c) (i) Open Access

\section{Abstract}

This study clarified the characteristic autonomic nervous activity of institutionalized elders diagnosed with dementia using Hasegawa's Dementia Scale-Revised. Twenty-six healthy adult persons (HPs) in their $20 \mathrm{~s}-40 \mathrm{~s}$ met the inclusion criteria, and 16 persons $(27.6 \pm 8.2$ years old) completed the research procedure. Of 70 persons with dementia (PDs) residing at the one geriatric health services facilities, only 24 persons met the inclusion criteria, and only nine $(\mathrm{N}=9,83.44 \pm$ 9.45 years old) completed the procedure. Actigraph and ambulatory electrocardiographic instruments measuring autonomic nervous activity were attached to the subjects for 24 hours. Activities and behaviors of PDs and HPs were observed by clinically experienced staff nurses and care workers. High frequency (HF) power indicating parasympathetic activity and LF/HF ratio indicating sympathetic activity were calculated. When awake, PDs' LF/HF ratio was significantly lower than HP's $(Z=-2.60, p<0.01)$, showing significant differences in the LF/HF ratios between waking and sleeping, more than those of the PDs $(p<0.001)$. Similarly, when awake, significant positive correlations were observed in the LF/HF ratio and actigraph activity count (AC) in 11 HPs and 3 PDs (range $r=0.17$ to $0.49, p<0.05$ ); however, significant negative correlation was found in $\mathrm{HF}$ and AC of 12 HPs and 3 PDs (range $r=-0.55$ to $-0.18, p<0.05$ ). While sleeping, significant positive correlations were observed in LF/HF and AC of $3 \mathrm{HPs}$ and 1 PD (range $r=0.35$ to $0.42, p<0.05$ ) and significant negative correlation was found in the HF and AC of $1 \mathrm{HP}(\mathrm{r}=-0.32, \mathrm{p}<0.001)$ and 1 $P D(r=-0.32, p<0.05)$. The mean value of $L F / H F$ in a wakeful state was significantly lower for PDs than HPs. Combined results of behavioral observation, actigrapy and heart rate variability (HRV) analyses suggested that PDs showed positive correlations between LF/HF and AC in a wakeful state. Compared to those who showed no positive correlation, they did not require much nursing care.

\footnotetext{
"Corresponding author.
} 


\title{
Keywords
}

\author{
Elderly Dementia, Actigraph, Heart Rate Variability, Autonomic Nervous Activity, Behavior \\ Observation, Care Activities
}

\section{Introduction}

In Japan, 20 percent of elderly persons with dementia who enjoy nursing service benefits from the nursing care insurance system live in neighborhood nursing facilities [1]. Geriatric health services facilities are places where many elderly Japanese persons with dementia are admitted in order to receive nursing services that might enable them to live at home again [2]. However, in many situations it is difficult for elderly persons to return home [3], because they do not have family members available to take care of them [4].

Facilities that accept elderly persons with dementia offer rehabilitation and recreation programs to enable them to maintain and improve their physical functioning and to alleviate symptoms of dementia [5]-[7]. Treiberet $e t$ al. [8] reported that active cognitive stimulation might keep the functioning of persons with dementia from outright degeneration. Physical activities such as walking, housework or gardening were found to be effective for persons with dementia suffering from depression [9]. Without intentional stimulation, persons with dementia can remain inactive for prolonged periods of time, resulting in the lowering of physical and cognitive functions. In addition to the primary symptoms of memory disorder and disorientation [10] [11], patients with Alzheimer's dementia, also show behavioral and psychological symptoms of dementia (BPSD) [12] [13] such as daytime drowsiness, nighttime delirium, and irritability [14] [15].

In a study of the autonomic nervous activities of persons with dementia, music therapy was found effective in alleviating BPSD [16], wherein high frequency (HF) power was significantly increased, while the low frequency LF/HF ratio was slightly decreased [17]. Passive and interactive music interventions were also found to cause short-term parasympathetic dominance [16]. Aroma therapy, a passive intervention, was also found effective in activating HF, tending to create a relaxed state in the elderly person [18]. Using heart rate variability (HRV) analysis, five minutes of music therapy revealed that activation of HF power. However, no studies were found which showed the influence of lifestyle activities on autonomic nervous function of persons with dementia while in the nursing care facilities, for example, during activities including daily examinations of physical and mental activities during rehabilitation or conversational activities.

In healthy adults, parasympathetic nervous activity is predominant during sleep, whereas the sympathetic nervous system is active when awake. There was a strong negative correlation between activity counts (AC) and HF power, and a positive correlation between AC and LF/HF ratio [19]. In patients who suffered from sleep disturbance, these correlations were weaker [20]. Moreover, patients who slept well showed a significantly higher negative correlation of AC and HF [21]. The relationship between sleeping/waking states indicates that sleep is considered a condition in which there is high vagal activity and sympathetic activity is relatively quiescent [22]. Therefore, by comparing the results of patients with dementia and of healthy adults, and patients with dementia, it was considered able to clarify the features of elderly persons with dementia.

The purpose of this study was to clarify the characteristics of autonomic nervous activity of institutionalized elderly persons with dementia.

\section{Methods}

\subsection{Subjects}

\subsubsection{Healthy Persons (HPs)}

There were 26 healthy adult Japanese men and women $(\mathrm{N}=26)$ who met the inclusion criteria. This study recruited office workers and college students through the researcher's acquaintances and by word of mouth. Participants comprised 26 volunteer adult Japanese men and women aged in their $20 \mathrm{~s}$ to $40 \mathrm{~s}$ who described themselves as being healthy. Volunteers were included in the study if they met the following criteria: a normal monthly menstrual cycle, no menopausal symptoms, no eating disorder, and on a regular diet. Prospective volunteers working on rotating or night schedules, and those who were pregnant or menopausal were excluded from the study. Participants were instructed not to consume alcohol during the study period. The data were col- 
lected from August 2013 to May 2015. While data were completed for all participants, 10 participants were excluded because of erroneous data from mechanical and placement problems. Therefore, the data of 16 HPs were used for analysis ( 2 men and 14 women, $27.63 \pm 8.21$ years old, $\mathrm{N}=16$ ).

\subsubsection{Persons with Dementia (PDs)}

Persons with dementia were diagnosed using Hasegawa’s Dementia Scale-Revised (HDS-R) [24]. Out of 70 prospective subjects with dementia who resided at a geriatric health services facility, 23subjects met the inclusion criteria, and their range of HDS-R was 3 - 20 points. However 15 were disqualified because of incomplete data, and from equipment errors, including the inability to wear the actigraph at the wrist-watch area for 24 hours. This was also true for the electrocardiographic data. Therefore, only data from 9 women with Alzheimer's dementia and Vascular dementia were included (83.44 \pm 9.45 years old), and their range of HDS-R was 9 - 19 points. It can be noted that in addition to the primary symptoms of memory loss, patients with Alzheimer's dementia, and disorientation [10] [12] also showed BPSD [12] [23] such as daytime drowsiness, nighttime delirium, and irritability [14] [15]. Furthermore, four PDs took tranquilizers in order to alleviate neurotic and manic states, or BPSD, and another four PDs took minor tranquilizers to avoid depression and sleeplessness at night and to prevent chronic pains.

With a HDS-R score of 20 or less, dementia was suspected (30 is the highest score possible) [24]. Other meanings of the HDS-R include severity of dementia: a score of 20 - 15 points is categorized as Mild, 14 - 10 points is Moderate, 9 - 5 points is Moderately Severe, and below 5 points is Severe. Long-term care level [25] classify the status of persons with problematic behavior and decreased understanding. There are five levels. Level 1: those who need some support for transfer movement, level 2: those who need some assistance for overall life, level 3: those who need greater assistance for transfer movement, level 4: those who cannot move or excrete by themselves, level 5: those who cannot move, excrete, or eat by themselves (see Table 1).

\subsection{Data Collection Period}

The investigation period was from June 2012 to March 2015. Because of the rarity of the conditions required to qualify as subjects the study, it took nearly 3 years to collect the data.

\subsection{Measurement Times and Methods of Classification between Waking/Sleeping Time}

The actigraphic and electrocardiographic devices were attached to all subjects for 24 hours. Measurement time was as follows: A: 9:00 AM - 9:00 AM the following day; Measurement time B from 18:00 - 18:00 the following

Table 1. Clinical characteristics of persons with dementia.

\begin{tabular}{|c|c|c|c|c|c|c|c|c|c|}
\hline \multirow{2}{*}{$\begin{array}{l}\text { Subject } \\
\text { number }\end{array}$} & \multirow[b]{2}{*}{ Age } & \multirow[b]{2}{*}{ Sex } & \multirow{2}{*}{$\begin{array}{l}\text { Type of } \\
\text { dementia }\end{array}$} & \multirow[b]{2}{*}{ HDS-R } & \multirow{2}{*}{$\begin{array}{l}\text { Long-term } \\
\text { care level }\end{array}$} & \multirow{2}{*}{$\begin{array}{c}\text { Communication } \\
\text { ability }\end{array}$} & \multicolumn{3}{|c|}{ Internal remedy affects autonomic nervous activity } \\
\hline & & & & & & & $\begin{array}{c}\text { Major } \\
\text { tranquilizers }\end{array}$ & $\begin{array}{c}\text { Minor } \\
\text { tranquilizers }\end{array}$ & Others \\
\hline 1 & $90 \mathrm{~s}$ & $\mathrm{~F}$ & ALZ & 10 & 2 & Goodness & & $\begin{array}{c}\text { Etizolam, } \\
\text { Amitriptyline }\end{array}$ & Loxoprofen \\
\hline 2 & $80 \mathrm{~s}$ & $\mathrm{~F}$ & ALZ & 10 & 4 & No-good & $\begin{array}{l}\text { Quetiapine, } \\
\text { Risperidone }\end{array}$ & & Memantine \\
\hline 3 & $60 \mathrm{~s}$ & $\mathrm{~F}$ & VD & 16 & 4 & Passivity & & & \\
\hline 4 & $80 \mathrm{~s}$ & $\mathrm{~F}$ & ALZ & 9 & 1 & Goodness & Risperidone & Diazepam & \\
\hline 5 & $70 \mathrm{~s}$ & $\mathrm{~F}$ & ALZ & 16 & 2 & Passivity & Aripiprazole & $\begin{array}{l}\text { Etizolam, } \\
\text { Brotizolam }\end{array}$ & Sodium valproate \\
\hline 6 & $90 \mathrm{~s}$ & $\mathrm{~F}$ & ALZ & 9 & 4 & Goodness & Quetiapine & & \\
\hline 7 & $80 \mathrm{~s}$ & $\mathrm{~F}$ & ALZ & 19 & 1 & Goodness & & $\begin{array}{l}\text { Trazodone, } \\
\text { Mirtazapine }\end{array}$ & \\
\hline 8 & $90 \mathrm{~s}$ & $\mathrm{~F}$ & ALZ & 17 & 2 & Passivity & & & \\
\hline 9 & $70 \mathrm{~s}$ & $\mathrm{~F}$ & VD & 19 & 1 & Goodness & & & \\
\hline
\end{tabular}

Notes: Long-term care level, 5 most severe, 4 severe, 3 need care, 2 need some care, 1 slightly care need. Abbreviations: F = Female, ALZ = Alsheimer's disease, VD = Vascular dementia, HDS-R = Hasegawa's Dementia Scale for Revised. 
day. Because there was no large difference between LF/HF and HF of waking/sleeping time in both measurement times (A and B), the decision was to categorize them as one group. Therefore, the measurement time for PDs was set to be 9:00 AM - 9:00 AM the following day.

\subsection{Description of Measurement Items}

The University of Tokushima Hospital Clinical Study Ethical Review Board approved this study. No harm to the subjects could be identified. Return of the survey implied that the subjects gave consent. The subjects were notified that privacy would be protected; only aggregate data would be used in reporting the findings.

\subsubsection{Actigraphy}

Actigraphy is a measurement procedure that is used to assess the balance between waking time and sleeping time, and the conditions of sleep disturbance [26]. In this study, a portable micro mini-type actigraph (Ambulatory Monitoring, Inc., Ardsley, NY, USA) was attached to each subject's non-dominant arm for 24 hours. The actigraph was worn on the wrist like a watch. It electronically measures the number of movements exceeding $0.01 \mathrm{~g}$ (gravitational force per minute of recording).

An epoch length of 60 seconds was used from the vertical axis. The activity counts (AC) from the vertical axis of an accelerometer represent a digital integration of the positive and negative vertical displacement of the body's center of mass per unit time [27] [28]. Sleep or wake time was judged by Sleep-scoring algorithm of the AW2 software (Ambulatory Monitoring, Inc.) [29]. The time during in which the subjects were wearing the actigraph was divided into "up" (daytime activity) intervals, defined as the period of time subjects reported being out of bed, and "down" (sleep) intervals, defined as the period during which subjects were in bed. AC from the actigraph was used as indicators of activity levels. The actigraph was used in the zero crossing mode to detect a micromotion.

\subsubsection{Heart Rate Variability}

$\mathrm{HRV}$ is an efficient noninvasive method used to investigate autonomic nervous system function and cardiovascular control while awake or during sleep. In this study, electrodes were placed at strategic locations on the chest and recording was done via a Holter electrocardiographic monitor for 24 hours. The HF component also served as an indicator of parasympathetic nervous system activity. LF/HF indicates sympathetic nervous system activity.

\subsubsection{Method of Collecting Life Records of the HP Group and Observing Behaviors of Those of the PD Group}

Life records of the HP group were shown along with the records taken by actigraphy and by electrocardiographic devices. In terms of the life records, activity details and the necessary time, the time when subjects went to bed, and the time when they arose were described on the autographic recording surveys. The HPs activity statuses were further checked during the measurement period by interviewing them after the examination was over. During the examination period, the group of HP led their normal lives.

Methods of observing PD’s behaviors are as follows: During the daytime (9:00 - 17:00), four nurses who had more than five years' clinical experience observed the activities of PD while at nighttime (17:00 - 9:00) ten care workers cooperating with researchers who had more than five years' clinical experience replaced them. They recorded PD's activity status (including getting up, sleeping and walking) along with their expressions and behaviors. During the time of observation, they maintained a certain distance between the subjects in case they should become too nervous. They observed how PDs could communicate with others, their tendency of drowsiness during the day, their tendency of waking during the night, as well as their activity levels. Regarding their activity level, they checked how PDs were capable of executing their actions to the end without breaks, how PDs were motivated to voluntarily participate in activities, and how they could communicate with others.

These records were used in order to enhance the credibility of the analysis results of the actigraphy and HRV.

\subsection{Data Collection}

The researcher explained the procedures for data collection to the subjects who met the inclusion criteria. In order to obtain accurate measurements, subjects were instructed on how to use the actigraphic and electrocardio- 
graphic devices. These were all done by the researchers (SF, YY, TT, and MS).

\subsection{The Mental Interference to PDs}

In the PD group, mental interference, including intentional communications, was conducted in addition to rehabilitation (physical interference) and recreation (the mental interference), both of which were offered in the normal nursing services facilities. Researchers with nurse's licenses showed pictures (babies, animals, and landscape) to PDs and talked with them for 30 minutes asking them what they felt or associated with seeing the pictures.

\subsection{Analysis Methods}

\subsubsection{Analysis Methods for Actigraph and Heart Rate Variability}

Actigraph and HRV data were analyzed using dedicated computer analysis programs, and the results were recorded graphically, enabling visual assessment. Such visual representation provided clear reliable data.

The data obtained from the actigraph were analyzed using AW2 software (Ambulatory Monitoring, Inc.). The AC of actigraph was matched with the HRV data produced over 5 minute intervals. HRV was analyzed using the Mem Calc/CHIRAM procedure (GMS Co, Tokyo, Japan). The HRV results included the LF component $(0.04-0.15 \mathrm{~Hz})$ and the HF component $(0.15-0.50 \mathrm{~Hz})$, as extracted by power-spectrum density.

\subsubsection{Statistical Analysis}

1) To clarify a difference of LF/HF and HF during waking and sleeping between HPs and PDs, an examination of the equal variances was conducted, as a result, it was conducted either Student's t-test or Welch's t-test. 2) To compare LF/HF and HF during waking and sleeping of HPs and PDs, the Mann-Whitney's U test was conducted. 3) To clarify the relation between autonomic nervous activity and AC, Pearson's correlation coefficient was calculated. 4) To clarify the difference of influences that daily activities gave to the autonomic nervous activity, Fisher's exact test was conducted by separating subjects into those who showed significant differences $(\mathrm{p}<0.001)$ of HF and LF/HF during waking and sleeping. 5) To illustrate typical examples of PDs (LF/HF during waking correlate strongly with AC or not). The statistical analysis was carried out using Statistical Package for the Social Sciences version 20 software (PASW Statistics for Windows, SPSS Inc., Chicago, IL, USA). Statistical significance was set at $\mathrm{p}<0.05$.

\subsection{Ethical Consideration}

The data collection procedure was performed following the Private Information Protection Law, with approval from the Tokushima University Hospital Ethics Board (approval number 2039). The purpose and methods used in the study were explained to all subjects and their guardian. Subjects were assured that their personal information was protected, the report would be done as an aggregate, and used only for research purposes. Informed consents were obtained prior to the commencement of the study.

\section{Results}

\subsection{Differences between during Waking and Sleeping in HPs and PDs}

The compared results of mean values of LF/HF and HF during waking and sleeping in HPs and PDs: The LF/HF mean value of HP was significantly higher as compared to the PD during waking time $(Z=-2.60, p<0.01)$. Significant differences in HF of waking time and LF/HF and HF in sleeping time were not observed between the HPs and PDs (Table 2-Mann-Whitney's U test).

Table 2-Pearson's $r$ value also showed the correlation between autonomic nervous activities and AC. When awake, significant positive correlation between LF/HF and AC was observed in 11 HPs (range $r=0.20$ to 0.49 , $\mathrm{p}<0.05)$. The following data indicated that when awake, 11 out of 16 HPs showed a significant positive correlation between their LF/HF and AC ( $\mathrm{p}<0.001$; 9 persons, $\mathrm{p}<0.05 ; 2$ persons). Five HPs showed no significant correlation.

When awake, significant positive correlation between LF/HF and AC was observed in 3 PDs: No. $4(r=0.32$, $\mathrm{p}<0.001)$, No. $7(\mathrm{r}=0.17, \mathrm{p}<0.05)$, and No. $8(\mathrm{r}=0.31, \mathrm{p}<0.001)$. However, six PDs showed no significant 
Table 2. Compared results of HPs and PDs during waking and sleeping time.

\begin{tabular}{|c|c|c|c|c|c|c|c|c|c|c|c|}
\hline \multirow{2}{*}{\multicolumn{2}{|c|}{$\begin{array}{c}\text { Mann-Whitney’s } \\
\text { U-test }\end{array}$}} & \multicolumn{4}{|c|}{ HPs $(\mathrm{N}=16)$} & \multicolumn{4}{|c|}{ PDs $(\mathrm{N}=9)$} & \multirow{3}{*}{$\begin{array}{c}\begin{array}{c}\mathbf{Z} \\
\text { value }\end{array} \\
-2.60\end{array}$} & \multirow{3}{*}{\begin{tabular}{|c|} 
p-value \\
$* *$ \\
\end{tabular}} \\
\hline & & \multirow{2}{*}{$\begin{array}{c}\begin{array}{c}\text { Median } \\
\text { value }\end{array} \\
3.37 \\
\end{array}$} & \multirow{2}{*}{\begin{tabular}{|c|}
$25 \%$ \\
value
\end{tabular}} & \multirow{2}{*}{\begin{tabular}{|c|}
$75 \%$ \\
value \\
6.09 \\
\end{tabular}} & \multirow{2}{*}{\begin{tabular}{c|} 
Range \\
$2.19-8.16$
\end{tabular}} & \multirow{2}{*}{$\begin{array}{c}\begin{array}{c}\text { Median } \\
\text { value }\end{array} \\
1.78 \\
\end{array}$} & \multirow{2}{*}{\begin{tabular}{r|}
$\begin{array}{c}25 \% \\
\text { value }\end{array}$ \\
1.36 \\
\end{tabular}} & \multirow{2}{*}{\begin{tabular}{|c|}
$\mathbf{7 5 \%} \%$ \\
value
\end{tabular}} & \multirow{2}{*}{$\begin{array}{c}\text { Range } \\
0.84-5.66\end{array}$} & & \\
\hline Wakig & $\mathrm{LF} / \mathrm{HF}$ & & & & & & & & & & \\
\hline & $\begin{array}{c}\mathrm{HF} \\
\left(\mathrm{msec}^{2}\right)\end{array}$ & 343.61 & 188.01 & 434.73 & 101.09 - 677.90 & 82.52 & 76.03 & 694.47 & $15.69-3591.82$ & -1.19 & n.s. \\
\hline \multirow{2}{*}{$\begin{array}{l}\text { Sleeping } \\
\text { time }\end{array}$} & LF/HF & 1.59 & 0.91 & 2.23 & $0.81-2.94$ & 1.62 & 0.99 & 2.87 & $0.67-4.17$ & -0.28 & n.s. \\
\hline & $\underset{\left(\mathrm{msec}^{2}\right)}{\mathrm{HF}}$ & 759.72 & 470.31 & 1102.05 & $160.04-1774.53$ & 205.50 & 82.42 & 1440.85 & $18.21-4027.65$ & -1.53 & n.s. \\
\hline \multirow{2}{*}{\multicolumn{2}{|c|}{$\begin{array}{l}\text { Pearson's r values } \\
\text { of correlation }\end{array}$}} & \multicolumn{4}{|c|}{ HPs $(\mathrm{N}=16)$} & \multicolumn{4}{|c|}{ PDs $(\mathrm{N}=9)$} & \multirow{2}{*}{\multicolumn{2}{|c|}{ p-value }} \\
\hline & & $\begin{array}{c}\text { Median } \\
\text { value }\end{array}$ & $\begin{array}{l}25 \% \\
\text { value }\end{array}$ & $\begin{array}{c}75 \% \\
\text { value }\end{array}$ & Range & $\begin{array}{c}\text { Median } \\
\text { value }\end{array}$ & $\begin{array}{l}25 \% \\
\text { value }\end{array}$ & $\begin{array}{l}75 \% \\
\text { value }\end{array}$ & Range & & \\
\hline \multirow[t]{2}{*}{$\begin{array}{l}\text { Wakig } \\
\text { time }\end{array}$} & $\begin{array}{l}\mathrm{LF} / \mathrm{HF} \\
\text { and AC }\end{array}$ & 0.26 & 0.17 & 0.35 & $-0.15-0.49$ & 0.09 & 0.04 & 0.17 & $-0.34-0.32$ & \multirow{4}{*}{\multicolumn{2}{|c|}{$\S$}} \\
\hline & $\begin{array}{l}\text { HF and } \\
\text { AC }\end{array}$ & -0.26 & -0.40 & -0.16 & $-0.55-0.14$ & -0.14 & -0.19 & -0.07 & $-0.25-0.27$ & & \\
\hline \multirow[t]{2}{*}{$\begin{array}{l}\text { Sleeping } \\
\text { time }\end{array}$} & $\begin{array}{l}\mathrm{LF} / \mathrm{HF} \\
\text { and AC }\end{array}$ & 0.08 & 0.02 & 0.12 & $-0.25-0.39$ & 0.04 & 0.01 & 0.11 & $-0.24-0.42$ & & \\
\hline & $\begin{array}{l}\text { HF and } \\
\text { AC }\end{array}$ & -0.84 & -0.17 & 0.00 & $-0.32-0.23$ & -0.03 & -0.13 & 0.18 & $-0.19-0.28$ & & \\
\hline
\end{tabular}

Notes: ${ }^{* *} \mathrm{p}<0.01$, n.s., not significant, ${ }^{\S}$ If the value of $\mathrm{r}$ of the correlation coefficient, significance levels were: more than 0.16 was level at $\mathrm{p}<0.05$; more than 0.20 was significance level at $\mathrm{p}<0.01$; and more than 0.3 was significant level at $\mathrm{p}<0.001$. Abbreviations: LF $=$ Low frequency power, $\mathrm{HF}=$ High frequency power, $\mathrm{PD}=$ Persons with dementia, $\mathrm{HP}=$ Healthy persons .

correlation. However, when awake, significant negative correlation between HF and AC was observed in 12 HPs (range $r=-0.55$ to $-0.18, p<0.05$ ). The following showed the data: 12 out of 16 HPs showed significant negative correlations to HF and AC ( $\mathrm{p}<0.001$; 8 persons, $\mathrm{p}<0.01$; one person, $\mathrm{p}<0.05$; 3 persons). Four HPs' data did not show a significant correlation.

However, during sleeping time, 2 out of 16 HPs showed a significant positive correlation between the LF/HF and AC $(\mathrm{p}<0.001)$. Fourteen HPs showed no significant correlation. Also, one HP out of 16 HPs showed a significant negative correlation to HF and AC $(\mathrm{p}<0.001)$. Data from fifteen HPs' did not show a significant correlation.

Significant negative correlation between HF and AC was observed in 3 PDs (range $r=-0.25$ to $-0.19, p<$ $0.05)$ during waking time. The following shows the data: PD subjects No. $4(\mathrm{r}=-0.25, \mathrm{p}<0.01)$, No. 7 ( $\mathrm{r}=$ -0.23 , $\mathrm{p}<0.01)$, and No. 9 ( $\mathrm{r}=-0.19, \mathrm{p}<0.05)$ showed a significant negative correlation to HF and AC. However, other PDs did not show a significant correlation.

During sleeping time, PD subject No. 5 showed a significant positive correlation between the LF/HF and AC $(r=0.42, p<0.001)$, and a significant negative correlation to HF and AC $(r=-0.19, p<0.05)$.

\subsection{The Number of HPs Who Showed Significant Differences between Waking and Sleeping Time in LF/HF and HF Compared with PDs}

Table 3 shows the number of HPs with significant differences in LF/HF between waking and sleeping more than that of PD ( $\mathrm{p}<0.001)$. No significant difference was observed between HPs and PDs in HF. One PD, however, showed a higher HF value during awake than asleep.

\subsection{Typical Examples of Actigraphic Data, and HRV in 1 HP and 2 PDs}

Figure 1 shows the typical example of a positive correlation between LF/HF and AC during the day in HP $(\mathrm{r}=$ $0.38, \mathrm{p}<0.001$ ).

Figure 2 shows typical subject in PD with a positive correlation between LF/HF and AC during the day $(\mathrm{r}=$ 0.32 , $\mathrm{p}<0.001$ ) underwent rehabilitation for 1 hour and 2 minutes. The rehabilitation included upper and lower 
Table 3. The number of HPs who showed a significant difference in LF/HF and HF between waking and sleeping time compared to PDs.

\begin{tabular}{|c|c|c|c|c|c|c|}
\hline & & $\begin{array}{c}\text { Significant differences } \\
(\%)\end{array}$ & $\begin{array}{c}\text { No significant } \\
\text { differences (\%) }\end{array}$ & $\begin{array}{r}\text { Reverse }^{\mathrm{a}} \\
(\mathrm{N})(\%)\end{array}$ & $\chi^{2}$-value & p-value \\
\hline \multirow[t]{2}{*}{ LF/HF } & HPs $(N=16)$ & 15 (93.75) & $1(6.25)$ & (0) $(0)$ & 7.61 & $* * *$ \\
\hline & PDs $(N=9)$ & $4(44.44)$ & $5(55.56)$ & $(0)(0)$ & & \\
\hline \multirow[t]{2}{*}{$\mathrm{HF}\left(\mathrm{msec}^{2}\right)$} & HPs $(\mathrm{N}=16)$ & $16(100)$ & $0(0)$ & (0) (0) & 5.43 & n.s. \\
\hline & PDs $(N=9)$ & 7 (77.78) & $2(22.22)$ & (1) (11.11) & & \\
\hline
\end{tabular}

Notes: Fisher's exact test, ${ }^{* * *} \mathrm{p}<0.001$, n.s., not significant, ${ }^{\mathrm{a}}$ The subject showed a higher HF power during awake than asleep. Abbreviations: $\mathrm{LF}=$ Low frequency power, HF = High frequency power, $\mathrm{PD}=$ Persons with dementia, $\mathrm{HP}=$ Healthy persons.

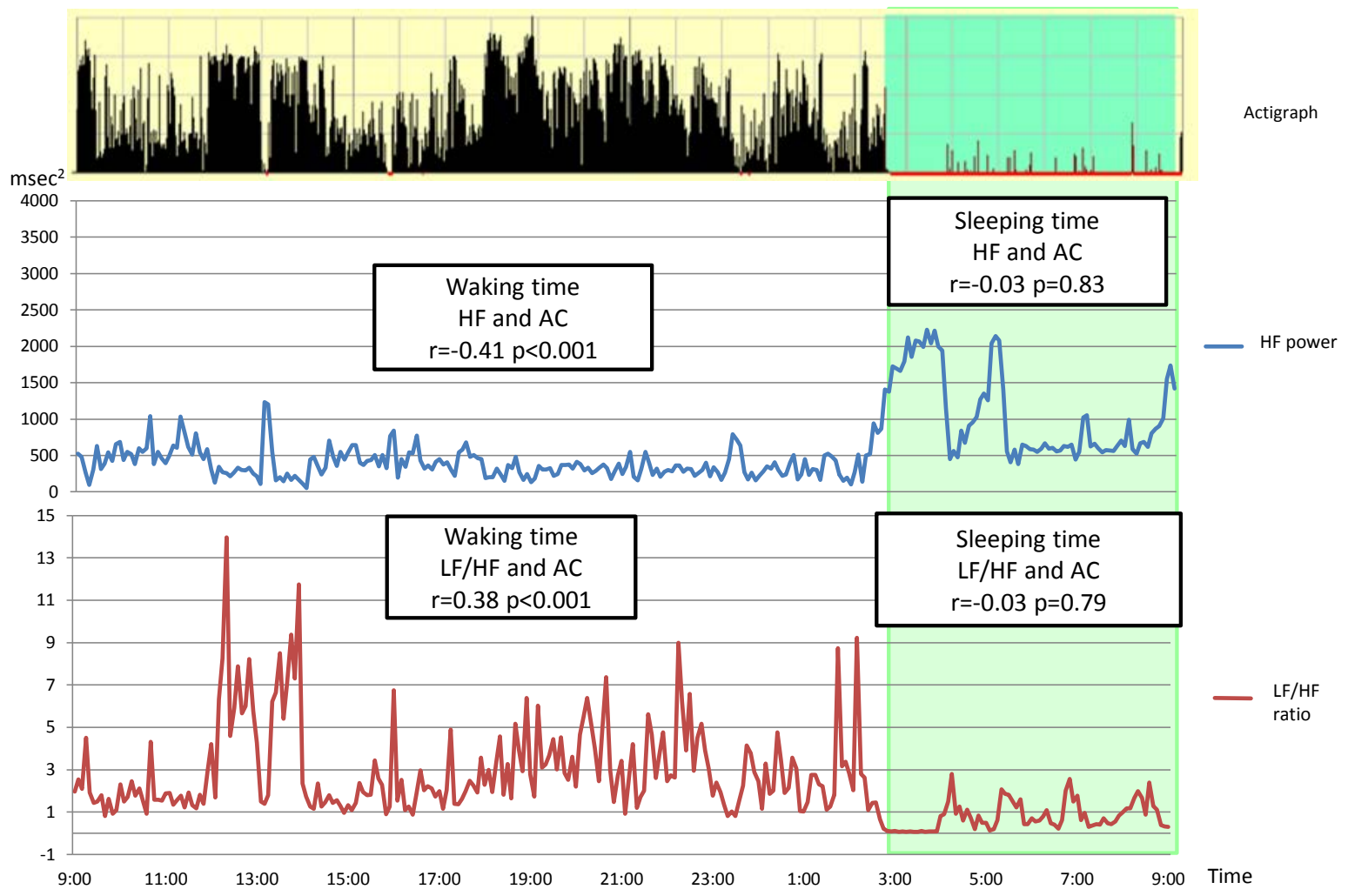

Notes: r, Pearson's r.

Abbreviations: LF, Low frequency power; HF, High frequency power; AC, activity count.

Figure 1. Typical example of significant positive correlation between LF/HF and AC in HP during waking time.

limb exercises and joint excursion training, as well as massage by an occupational therapist. The researcher intentionally communicated with the subject for 30 minutes. After lunch the subject took one tablet of Risperidone (0.5 mg) and one tablet of Diazepam (2 mg).

Figure 3 shows typical subject in PD with no positive correlation between LF/HF and AC during the day ( $\mathrm{r}=$ 0.04, $\mathrm{p}=0.72$ ) underwent rehabilitation for 1 hour and 6 minutes. The rehabilitation comprised of walking and upper limb exercises. This subject, however, often stopped doing exercises unless she was urged to do so by the occupational therapist. In addition, she constantly wandered around unless she was performing activities on a regular basis. The researcher also intentionally communicated with her for 30 minutes. The medicine taken by this subject after dinner was 1 tablet of Quetiapine (25 mg).

Figure 4 exhibits a typical PD (No. 5) with significant positive correlation between LF/HF and AC during sleeping time $(r=0.42, \mathrm{p}<0.001)$. However, Figure 5 shows a typical PD (No. 3 ) with no correlation between 


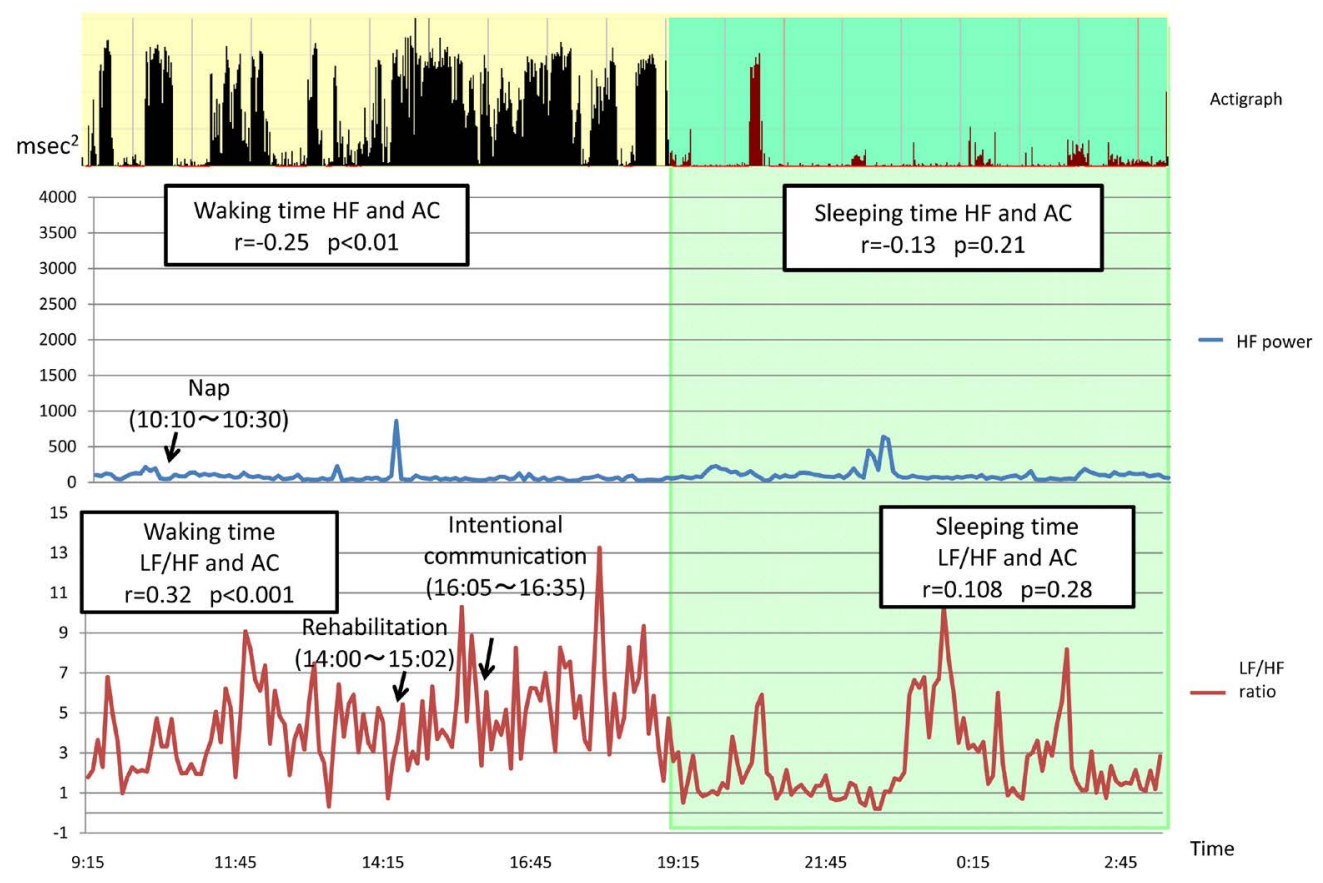

Notes: r, Pearson's r.

Abbreviations: $\mathrm{LF}$, Low frequency power; $\mathrm{HF}$, High frequency power; $\mathrm{AC}$, activity count.

Figure 2. Typical example of significant positive correlation between LF/HF and AC in PD subject No. 4 during waking time.

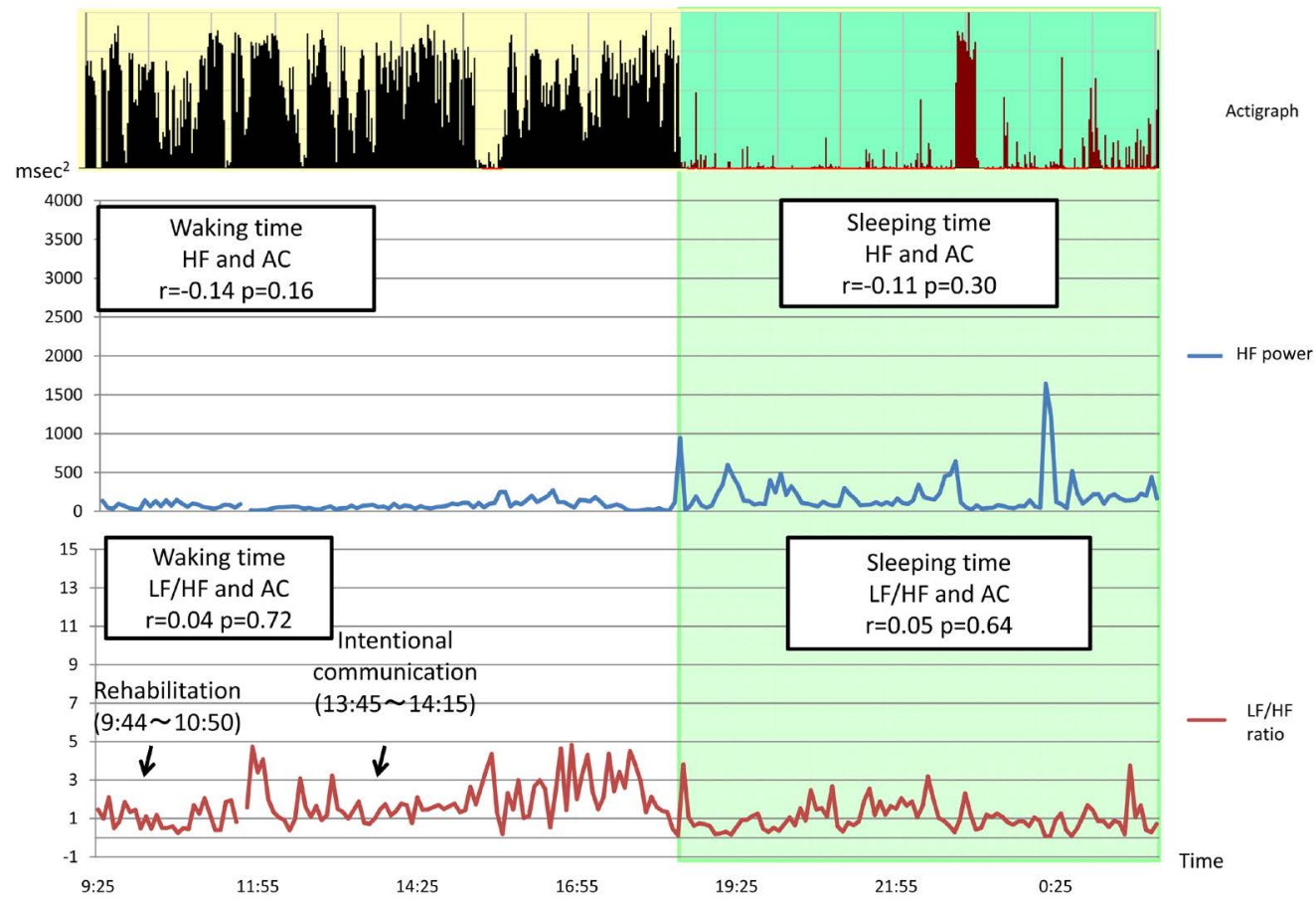

Notes: r, Pearson's r.

Abbreviations: $\mathrm{LF}$, Low frequency power; $\mathrm{HF}$, High frequency power; $\mathrm{AC}$, activity count.

Figure 3. Typical example of no significant positive correlation between LF/HF and AC in PD subject No. 6 during waking time. 


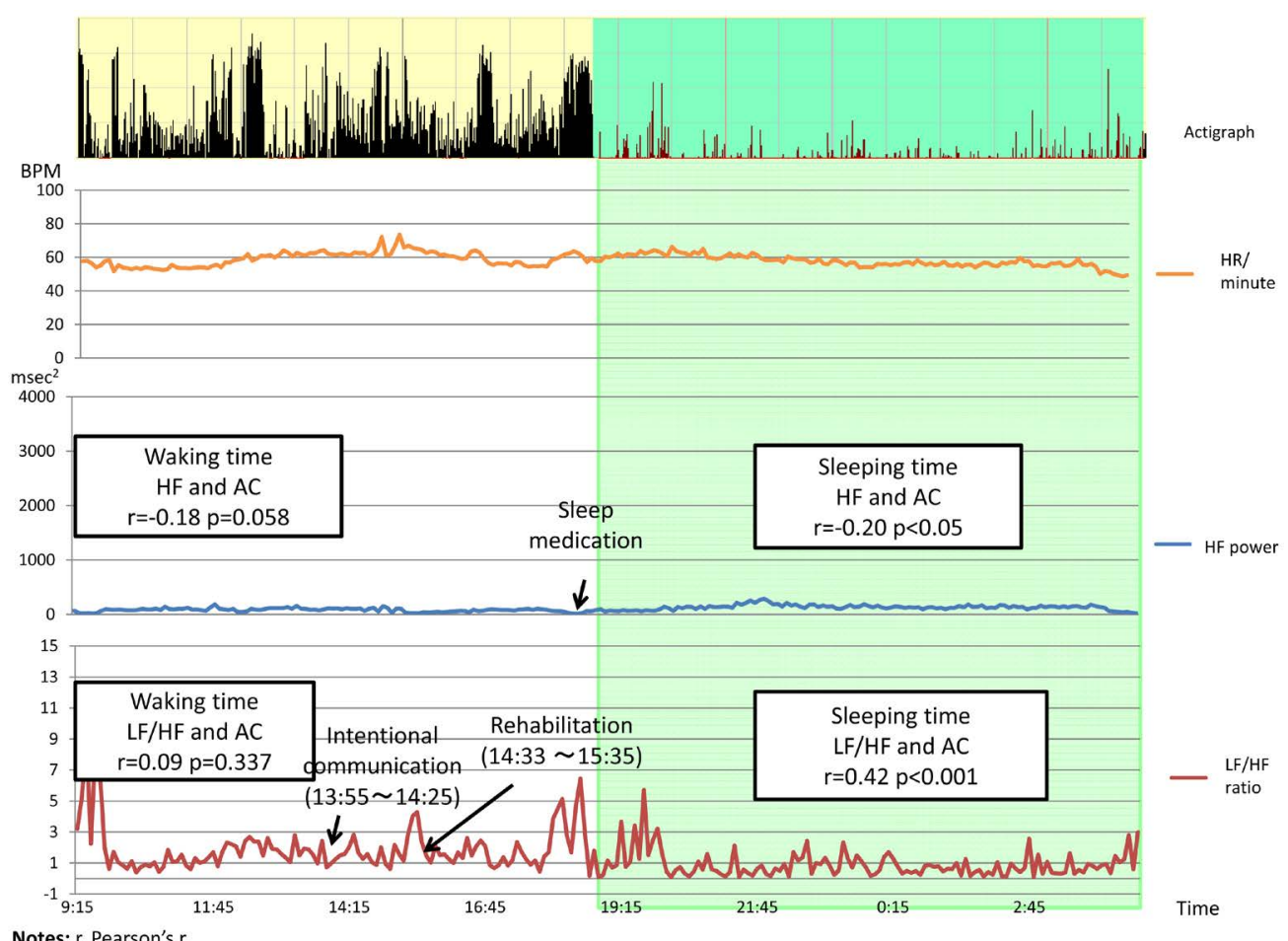

Notes: $r$, Pearson's $r$.

Abbreviations: $H R$, heart rate, BPM, beats per minute, LF, Low frequency power; $H F$, High frequency power; $A C$, activity count.

Figure 4. Typical example of significant positive correlation between LF/HF and AC in PD subject No. 5 during sleeping time.

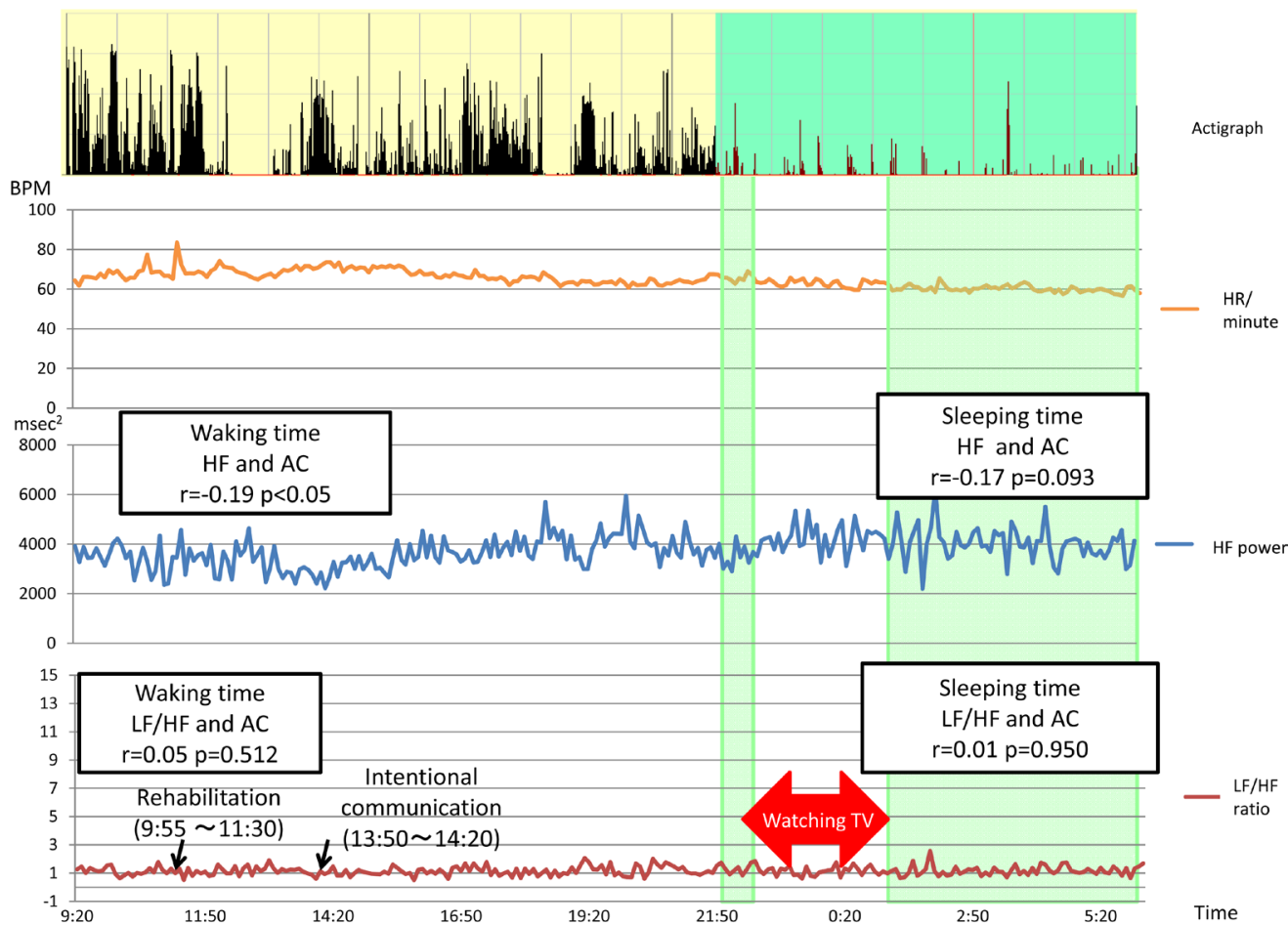

Notes: $r$, Pearson's $r$.

Abbreviations: $\mathrm{HR}$, heart rate, BPM, beats per minute, LF, Low frequency power; $\mathrm{HF}$, High frequency power; $A C$, activity count.

Figure 5. Typical example of no correlation between LF/HF and AC in PD subject No. 3 during sleeping time. 
LF/HF and AC during sleeping time $(r=0.01, p=0.95)$. According to observation data, the PD was watching $\mathrm{TV}$ while at bed rest, and during sleep period determined by actigraphy.

\subsection{Combined Results of Behavioral Observation, Autonomic Nervous Activity and AC}

The data obtained from behavioral observation of PDs are shown in descending order of the correlation coefficient between LF/HF and AC during waking hours (Tables 4-6). Table 4 (subject number: 4, 7, and 8) shows the subject with a positive correlation between LF/HF and AC during the day was motivated and actively engaged activities. They also maintained communication capabilities. Meanwhile, PDs (subject number: 1, 2, 3, 5, 6, and 9) without a positive correlation between LF/HF and AC during the day spent a great deal of time sedentary, lying in bed or sitting. However, they, showed a higher value of LF/HF during activities, such as rehabilitation and communication, than 5 minutes before she started those activities (Table 5 and Table 6).

\section{Discussion}

In the previous studies [30], the LF component and the LF/HF of PD were shown to be significantly decreased, compared to those of healthy elderly persons. Similarly, the sympathetic nervous activities of healthy persons in their twenties were shown to be enhanced more than those of healthy persons in their sixties [31].

In this study, as shown in Table 2-Mann-Whitney's U test, the average value of LF/HF in a wakeful state was significantly lower in PDs than for HPs. Apart from undergoing rehabilitation and communicating, as shown in Table 5, PDs reflected the sedentary lifestyle around the institution, watched TV, read newspapers and had meals. Furthermore, PDs who stayed at the institution rarely had opportunities to move their bodies and spent long hours maintaining the same position by sitting or lying in bed. As a result, it was considered their sympathetic nervous activity index became lower than those of HPs.

Table 4. Results of behavior observation, correlation between autonomic nervous activity and AC in PDs.

\begin{tabular}{|c|c|c|c|c|c|c|c|c|c|c|c|c|c|c|}
\hline \multirow{3}{*}{$\begin{array}{c}\text { Subject } \\
\text { number }\end{array}$} & \multirow{3}{*}{$\begin{array}{c}\text { Motivated } \\
\text { activity }^{\mathbf{a}} \\
\text { Good }\end{array}$} & \multirow{3}{*}{$\begin{array}{c}\text { Engaged } \\
\text { activity } \\
\text { Good }\end{array}$} & \multirow{3}{*}{$\begin{array}{c}\text { Communication } \\
\text { ability } \\
\text { Good }\end{array}$} & \multirow{3}{*}{$\begin{array}{c}\text { Wandered } \\
\text { around } \\
\text { Not } \\
\text { observed }\end{array}$} & \multirow{3}{*}{$\begin{array}{l}\text { Nap } \\
20 \mathrm{~min} \text {. } \\
\text { at AM }\end{array}$} & \multirow{3}{*}{$\begin{array}{c}\text { Night-time } \\
\text { awakening } \\
\text { Not } \\
\text { observed }\end{array}$} & \multicolumn{8}{|c|}{ Correlation $^{\mathrm{c}}$} \\
\hline & & & & & & & \multicolumn{2}{|c|}{$\begin{array}{c}\text { Waking } \\
\text { time } \\
\text { LF/HF } \\
\text { and AC }\end{array}$} & \multicolumn{2}{|c|}{$\begin{array}{c}\text { Waking } \\
\text { time } \\
\text { HF } \\
\text { and AC }\end{array}$} & \multicolumn{2}{|c|}{$\begin{array}{c}\text { Sleeping time } \\
\text { LF/HF } \\
\text { and AC }\end{array}$} & \multicolumn{2}{|c|}{$\begin{array}{c}\begin{array}{c}\text { Sleeping } \\
\text { time }\end{array} \\
\text { HF and AC }\end{array}$} \\
\hline & & & & & & & 0.32 & $* * *$ & -0.25 & $* *$ & n.s. & & n.s. & \\
\hline 7 & Good & Good & Good & $\begin{array}{c}\text { Not } \\
\text { observed }\end{array}$ & $\begin{array}{l}10 \text { min. at } \\
\text { PM }\end{array}$ & $\begin{array}{c}\text { Not } \\
\text { observed }\end{array}$ & 0.17 & $*$ & -0.23 & $* *$ & n.s. & & n.s. & \\
\hline 8 & Good & Good & Good & $\begin{array}{c}\text { Not } \\
\text { observed }\end{array}$ & $\begin{array}{c}\text { Not } \\
\text { observed }\end{array}$ & $\begin{array}{l}\text { Once for } \\
\text { bathroom }\end{array}$ & 0.31 & $* * *$ & n.s. & & n.s. & & n.s. & \\
\hline 1 & Good & Good & Good & $\begin{array}{c}\text { Not } \\
\text { observed }\end{array}$ & $\begin{array}{l}8 \text { min. at } \\
\mathrm{AM}\end{array}$ & $\begin{array}{c}\text { Not } \\
\text { observed }\end{array}$ & n.s. & & n.s. & & n.s. & & n.s. & \\
\hline 5 & Not good & Not good & Good & $\begin{array}{c}\text { Not } \\
\text { observed }\end{array}$ & $\begin{array}{c}\text { Not } \\
\text { observed }\end{array}$ & $\begin{array}{c}\text { Not } \\
\text { observed }\end{array}$ & n.s. & & n.s. & & 0.42 & $* * *$ & -0.19 & * \\
\hline 6 & Good & Not good & Good & $\begin{array}{c}\text { Not } \\
\text { observed }\end{array}$ & $\begin{array}{l}20 \text { min. at } \\
\text { PM }\end{array}$ & $\begin{array}{l}\text { Once for } \\
\text { bathroom }\end{array}$ & -0.16 & $*$ & n.s. & & n.s. & & n.s. & \\
\hline 2 & Not good & Not good & Not good & $\begin{array}{c}\text { Not } \\
\text { observed }\end{array}$ & $\begin{array}{c}\text { Not } \\
\text { observed }\end{array}$ & $\begin{array}{c}\text { Not } \\
\text { observed }\end{array}$ & -0.34 & $* * *$ & n.s. & & n.s. & & n.s. & \\
\hline 9 & Not good & Not good & Not good & $\begin{array}{c}\text { Not } \\
\text { observed }\end{array}$ & $\begin{array}{c}\text { Not } \\
\text { observed }\end{array}$ & 2 hours & n.s. & & -0.19 & $*$ & n.s. & & n.s. & \\
\hline 3 & Not good & Good & Good & Observed & $\begin{array}{c}\text { Not } \\
\text { observed }\end{array}$ & $\begin{array}{l}\text { Twice for } \\
\text { bathroom }\end{array}$ & n.s. & & n.s. & & n.s. & & n.s. & \\
\hline
\end{tabular}

Notes: ${ }^{\mathrm{a}}$ The ability which can be carried out without stopping decided activity; ${ }^{\mathrm{b}}$ Presence of independent participation in activity; ${ }^{\mathrm{c}}$ Shows pearson's $\mathrm{r}$ values of the correlation, ${ }^{* * *} \mathrm{p}<0.001,{ }^{* *} \mathrm{p}<0.01,{ }^{*} \mathrm{p}<0.05$. Abbreviations: LF = Low frequency power, HF = High frequency power, AC = activity count, $\mathrm{PD}=$ Persons with dementia, $\mathrm{HP}=$ Healthy persons, n.s. = not significant. 
Table 5. Contrasted results of behavior observation, HRV, and AC in PDs during day time.

\begin{tabular}{|c|c|c|c|c|c|c|c|c|c|c|c|c|c|c|c|c|c|c|c|c|}
\hline Day-time & $\begin{array}{l}\text { Subject } \\
\text { number }\end{array}$ & & 9:30 & $10: 00$ & $10: 30$ & $11: 00$ & $11: 30$ & $12: 00$ & $12: 30$ & $13: 00$ & $13: 30$ & $14: 00$ & $14: 30$ & $15: 00$ & $15: 30$ & $16: 00$ & $16: 30$ & $17: 00$ & $17: 30$ & $18: 00$ \\
\hline \multirow{9}{*}{ 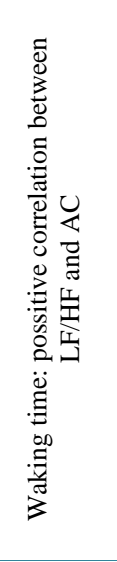 } & \multirow[t]{3}{*}{4} & & S & S & Aw & At & At & Ad & At & At & At & $\mathrm{Ar}$ & $\mathrm{Ar}$ & $\mathrm{Ar}$ & S & S & Ac & S & S & Ad \\
\hline & & $\begin{array}{l}\mathrm{LF} / \\
\mathrm{HF}\end{array}$ & $\downarrow$ & $\uparrow$ & $\downarrow$ & $\uparrow$ & $\downarrow$ & $\downarrow$ & $\downarrow$ & $\uparrow$ & $\uparrow$ & $\downarrow$ & $\uparrow$ & $\downarrow$ & $\uparrow$ & $\uparrow$ & $\uparrow$ & $\uparrow$ & $\downarrow$ & $\downarrow$ \\
\hline & & $\mathrm{HF}$ & $\downarrow$ & $\downarrow$ & $\uparrow$ & $\downarrow$ & $\uparrow$ & $\uparrow$ & $\uparrow$ & $\uparrow$ & $\uparrow$ & $\uparrow$ & $\downarrow$ & $\uparrow$ & $\uparrow$ & $\downarrow$ & $\downarrow$ & $\uparrow$ & $\uparrow$ & $\uparrow$ \\
\hline & \multirow[t]{3}{*}{7} & & & $\mathrm{Ae}$ & $\mathrm{Bn}$ & B & $\mathrm{S}$ & $\mathrm{Ae}$ & $\mathrm{Bn}$ & B & S & $\mathrm{Ar}$ & $\mathrm{Aw}$ & $\mathrm{Bn}$ & $\mathrm{Bn}$ & Ac & S & $\mathrm{Ab}$ & S & $\mathrm{Ad}$ \\
\hline & & $\begin{array}{l}\mathrm{LF} / \\
\mathrm{HF}\end{array}$ & & $\downarrow$ & $\uparrow$ & $\downarrow$ & $\uparrow$ & $\downarrow$ & $\downarrow$ & $\downarrow$ & $\downarrow$ & $\downarrow$ & $\uparrow$ & $\rightarrow$ & $\downarrow$ & $\uparrow$ & $\downarrow$ & $\uparrow$ & $\uparrow$ & $\uparrow$ \\
\hline & & $\mathrm{HF}$ & & $\uparrow$ & $\downarrow$ & $\uparrow$ & $\downarrow$ & $\uparrow$ & $\downarrow$ & $\uparrow$ & $\uparrow$ & $\uparrow$ & $\downarrow$ & $\uparrow$ & $\uparrow$ & $\downarrow$ & $\uparrow$ & $\downarrow$ & $\downarrow$ & $\uparrow$ \\
\hline & \multirow[t]{3}{*}{8} & & At & At & $\mathrm{Sg}$ & $\mathrm{Ar}$ & Aw & Ad & At & At & At & Ac & S & At & At & At & At & At & Ad & Ad \\
\hline & & $\begin{array}{l}\mathrm{LF} / \\
\mathrm{HF}\end{array}$ & $\downarrow$ & $\downarrow$ & $\downarrow$ & $\uparrow$ & $\downarrow$ & $\downarrow$ & $\uparrow$ & $\uparrow$ & $\downarrow$ & $\downarrow$ & $\downarrow$ & $\downarrow$ & $\uparrow$ & $\downarrow$ & $\downarrow$ & $\uparrow$ & $\downarrow$ & $\downarrow$ \\
\hline & & $\mathrm{HF}$ & $\uparrow$ & $\downarrow$ & $\uparrow$ & $\downarrow$ & $\uparrow$ & $\downarrow$ & $\downarrow$ & $\downarrow$ & $\uparrow$ & $\uparrow$ & $\uparrow$ & $\uparrow$ & $\downarrow$ & $\uparrow$ & $\uparrow$ & $\downarrow$ & $\downarrow$ & $\uparrow$ \\
\hline \multirow{18}{*}{ 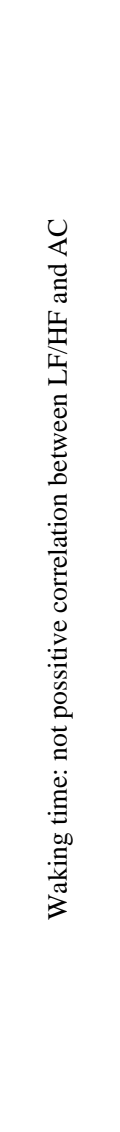 } & \multirow[t]{3}{*}{1} & & Ac & $\mathrm{Ar}$ & $\mathrm{Ar}$ & Awm & Awr & $\mathrm{Ad}$ & $S$ & $S$ & $\mathrm{~S}$ & Ac & Awr & Awr & $S$ & Ac & $\mathrm{S}$ & $S$ & $S$ & Ad \\
\hline & & $\begin{array}{l}\mathrm{LF} / \\
\mathrm{HF}\end{array}$ & $\uparrow$ & $\uparrow$ & $\downarrow$ & $\downarrow$ & $\downarrow$ & $\downarrow$ & $\uparrow$ & $\downarrow$ & $\downarrow$ & $\uparrow$ & $\uparrow$ & $\downarrow$ & $\downarrow$ & $\downarrow$ & $\downarrow$ & $\uparrow$ & $\uparrow$ & $\uparrow$ \\
\hline & & $\mathrm{HF}$ & $\downarrow$ & $\uparrow$ & $\uparrow$ & $\uparrow$ & $\uparrow$ & $\downarrow$ & $\downarrow$ & $\downarrow$ & $\uparrow$ & $\downarrow$ & $\downarrow$ & $\downarrow$ & $\uparrow$ & $\uparrow$ & $\uparrow$ & $\downarrow$ & $\uparrow$ & $\uparrow$ \\
\hline & \multirow[t]{3}{*}{5} & & $\mathrm{~S}$ & $\mathrm{~S}$ & Sg & As & As & $\mathrm{Ad}$ & Awm & B & B & Ac & Аа & $\mathrm{S}$ & $\mathrm{Ar}$ & At & At & At & At & $\mathrm{Ad}$ \\
\hline & & $\begin{array}{l}\text { LF/ } \\
\text { HF }\end{array}$ & $\downarrow$ & $\downarrow$ & $\uparrow$ & $\downarrow$ & $\downarrow$ & $\uparrow$ & $\downarrow$ & $\downarrow$ & $\downarrow$ & $\uparrow$ & $\downarrow$ & $\downarrow$ & $\uparrow$ & $\uparrow$ & $\downarrow$ & $\uparrow$ & $\downarrow$ & $\uparrow$ \\
\hline & & $\mathrm{HF}$ & $\uparrow$ & $\downarrow$ & $\uparrow$ & $\downarrow$ & $\uparrow$ & $\downarrow$ & $\uparrow$ & $\uparrow$ & $\downarrow$ & $\downarrow$ & $\uparrow$ & $\downarrow$ & $\downarrow$ & $\downarrow$ & $\downarrow$ & $\downarrow$ & $\uparrow$ & $\downarrow$ \\
\hline & \multirow[t]{3}{*}{6} & & Aw & $\mathrm{Ar}$ & $\mathrm{Ar}$ & $\mathrm{Ar}$ & Awm & Ad & B & B & B & Ac & S & B & Awm & B & B & $S$ & Ad & $S$ \\
\hline & & $\begin{array}{l}\mathrm{LF} / \\
\mathrm{HF}\end{array}$ & $\downarrow$ & $\uparrow$ & $\uparrow$ & $\uparrow$ & $\uparrow$ & $\downarrow$ & $\uparrow$ & $\downarrow$ & $\downarrow$ & $\mathrm{M}$ & $\downarrow$ & $\downarrow$ & $\downarrow$ & $\uparrow$ & $\downarrow$ & $\downarrow$ & $\downarrow$ & $\downarrow$ \\
\hline & & $\mathrm{HF}$ & $\uparrow$ & $\uparrow$ & $\downarrow$ & $\downarrow$ & $\uparrow$ & $\downarrow$ & $\downarrow$ & $\uparrow$ & $\downarrow$ & $\mathrm{M}$ & $\uparrow$ & $\downarrow$ & $\uparrow$ & $\uparrow$ & $\uparrow$ & $\uparrow$ & $\downarrow$ & $\downarrow$ \\
\hline & \multirow[t]{3}{*}{2} & & B & Ac & B & $\mathrm{Ar}$ & $\mathrm{Ar}$ & $\mathrm{Ad}$ & B & B & $\mathrm{Br}$ & B & $\mathrm{Aa}$ & $\mathrm{Ag}$ & $\mathrm{Ag}$ & $\mathrm{Br}$ & $\mathrm{Br}$ & $\mathrm{Br}$ & $\mathrm{S}$ & $\mathrm{Ad}$ \\
\hline & & $\begin{array}{l}\mathrm{LF} / \\
\mathrm{HF}\end{array}$ & $\downarrow$ & $\downarrow$ & $\uparrow$ & $\uparrow$ & $\downarrow$ & $\uparrow$ & $\downarrow$ & $\uparrow$ & $\uparrow$ & $\uparrow$ & $\downarrow$ & $\downarrow$ & $\uparrow$ & $\uparrow$ & $\uparrow$ & $\downarrow$ & $\downarrow$ & $\downarrow$ \\
\hline & & $\mathrm{HF}$ & $\uparrow$ & $\uparrow$ & $\downarrow$ & $\downarrow$ & $\downarrow$ & $\downarrow$ & $\uparrow$ & $\downarrow$ & $\downarrow$ & $\uparrow$ & $\downarrow$ & $\uparrow$ & $\downarrow$ & $\uparrow$ & $\downarrow$ & $\uparrow$ & $\uparrow$ & $\uparrow$ \\
\hline & \multirow[t]{3}{*}{9} & & $\mathrm{~S}$ & $\mathrm{Ar}$ & $\mathrm{Ar}$ & $\mathrm{Ar}$ & $\mathrm{Ar}$ & $\mathrm{Ad}$ & Ad & B & B & Ac & At & At & At & At & At & At & $S$ & Ad \\
\hline & & $\begin{array}{l}\mathrm{LF} / \\
\mathrm{HF}\end{array}$ & $\downarrow$ & $\uparrow$ & $\uparrow$ & $\downarrow$ & $\uparrow$ & $\uparrow$ & $\downarrow$ & $\uparrow$ & $\downarrow$ & $\downarrow$ & $\rightarrow$ & $\downarrow$ & $\uparrow$ & $\uparrow$ & $\downarrow$ & $\downarrow$ & $\uparrow$ & $\downarrow$ \\
\hline & & $\mathrm{HF}$ & $\uparrow$ & $\uparrow$ & $\downarrow$ & $\uparrow$ & $\downarrow$ & $\uparrow$ & $\uparrow$ & $\uparrow$ & $\uparrow$ & $\downarrow$ & $\downarrow$ & $\downarrow$ & $\downarrow$ & $\downarrow$ & $\downarrow$ & $\uparrow$ & $\downarrow$ & $\uparrow$ \\
\hline & \multirow[t]{3}{*}{3} & & S & $\mathrm{Ar}$ & $\mathrm{Ar}$ & $\mathrm{Ab}$ & Ac & Ad & Ac & $S$ & S & Ac & Aw & S & S & Ac & Ac & S & S & $\mathrm{Ad}$ \\
\hline & & $\begin{array}{l}\mathrm{LF} / \\
\mathrm{HF}\end{array}$ & $\downarrow$ & $\uparrow$ & $\rightarrow$ & $\downarrow$ & $\uparrow$ & $\uparrow$ & $\uparrow$ & $\uparrow$ & $\uparrow$ & $\downarrow$ & $\downarrow$ & $\uparrow$ & $\uparrow$ & $\uparrow$ & $\downarrow$ & $\uparrow$ & $\downarrow$ & $\downarrow$ \\
\hline & & HF & $\downarrow$ & $\downarrow$ & $\downarrow$ & $\downarrow$ & $\downarrow$ & $\uparrow$ & $\downarrow$ & $\uparrow$ & $\uparrow$ & $\uparrow$ & $\downarrow$ & $\downarrow$ & $\uparrow$ & $\downarrow$ & $\uparrow$ & $\downarrow$ & $\uparrow$ & $\uparrow$ \\
\hline
\end{tabular}

Notes: The data are shown in descending order of the correlation coefficient between LF/HF and AC during waking hours. Abbreviations: HRV = heart rate variability, LF = Low frequency, HF = High frequency, AC = activity count, PD = Persons with dementia, HP = Healthy persons, $\uparrow=$ The value becomes high compared with the value before 5 minutes, $\downarrow=$ The value becomes low compared with the value before 5 minutes, $\rightarrow=$ The value was same value before 5 minutes, $\mathrm{M}=$ missing value, $\mathrm{Aa}=$ Action (with assistance), $\mathrm{Ab}=$ Action (bathroom), $\mathrm{Ac}=$ Action (communication), Ad = Action (diet), Ae $=$ Action (in the elevator), Ag = Action (game), Ar = Action (rehabilitation), As = Action (sing), At = Action (watching TV), Aw = Action (warking), Awm = Action (wheelchair-mobile), Awr = Action (writing), B = Bed rest, Bn = Reading a newspaper (in the bed), Br = Rap at bed's fence, $\mathrm{S}=$ Sitting position, Sg = Gaze (sitting position).

As shown in Table 2-Pearson's r value, most of HPs showed positive correlation of the LF/HF and AC, and three out of 9 PDs had positive correlations between LF/HF and AC in a wakeful state when awake. As shown 
Table 6. Contrasted results of behavior observation, HRV, and AC in PDs during night time.

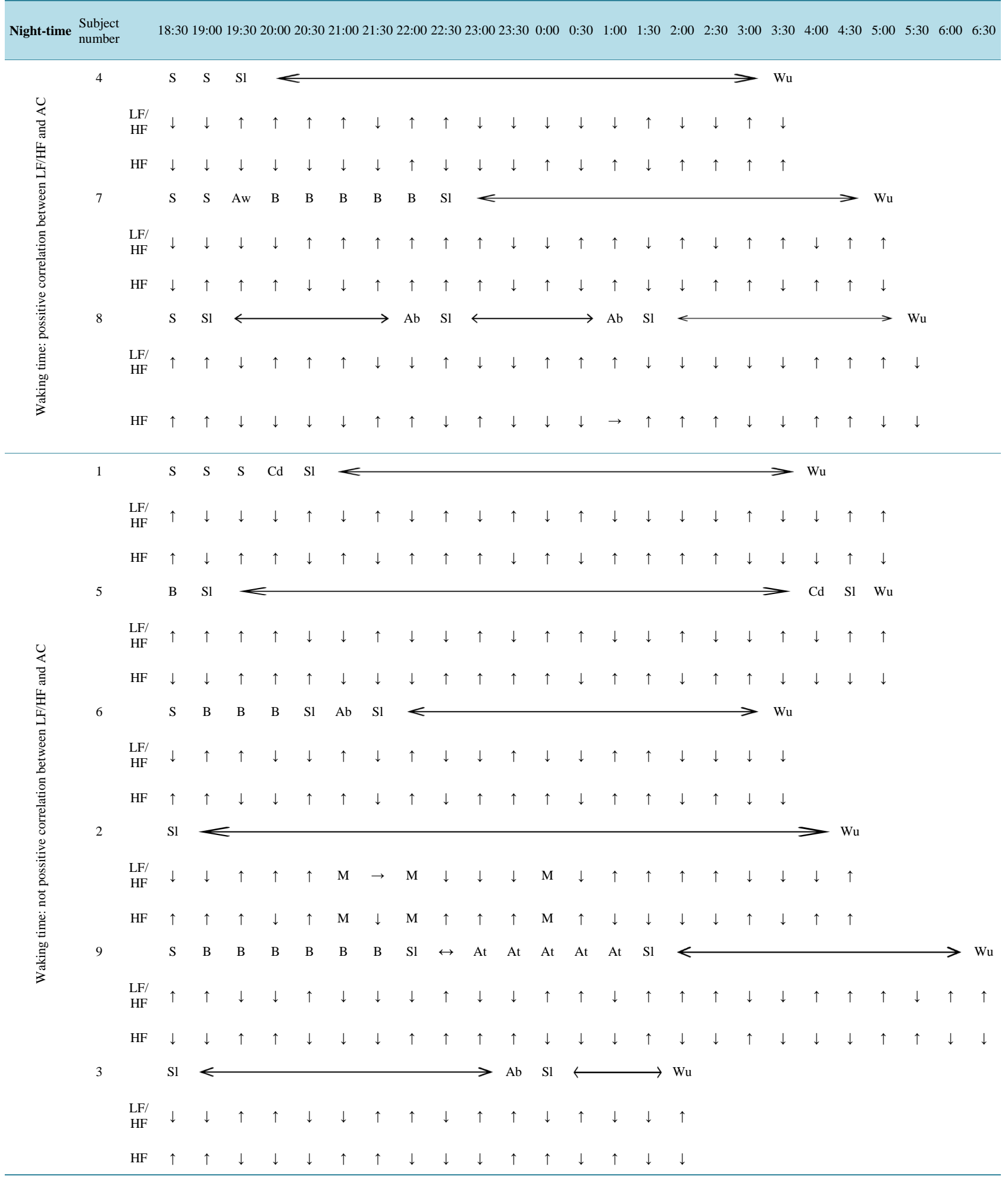

Notes: The data are shown in descending order of the correlation coefficient between LF/HF and AC during waking hours. Abbreviations: HRV = heart rate variability, LF $=$ Low frequency, $\mathrm{HF}=$ High frequency, $\mathrm{AC}=$ activity count, $\mathrm{PD}=$ Persons with dementia, HP $=$ Healthy persons, $\leftrightarrow=\mathrm{Sleeping}$ time, $\uparrow=$ The value becomes high compared with the value before 5 minutes, $\downarrow=$ The value becomes low compared with the value before 5 minutes, $\rightarrow=$ The value was same value before 5 minutes, $\mathrm{M}=$ missing value, $\mathrm{Ab}=$ Action (bathroom), At $=$ Action (watching $\mathrm{TV}$ ), $\mathrm{Aw}=\mathrm{Action}(\mathrm{warking}), \mathrm{B}=\mathrm{Bed}$ rest, $\mathrm{Cd}=\mathrm{Change}$ diapers, $\mathrm{S}=$ Sitting position, $\mathrm{Sl}=$ Sleep, $\mathrm{Wu}=$ Wake-up. 
in Table 4 and Table 5, those 3 PDs were actively involved in activities including watching television or reading newspapers and likewise maintained communication capabilities. These data suggest that a possibility exists that physical activities, as well as cognitive behavioral functions such as communication capabilities and assertiveness, affect sympathetic nervous activities.

Two PD subjects No. 4, and No. 7, their long term care level was 1 (slightly need care), showed positive correlation between LF/HF and AC, and negative correlation between HF and AC during waking time. Their motivated activity, engaged activity, and communication ability were good. Wandering around and night-time awakening was not observed.

PD subject No. 1, her long term care need level was level 2 (need some care), showed good motivated activity, engaged activity, and communication ability. Wandering around and night-time awakening was not observed. However, this condition was observed in similar situations as in PD subjects No. 4 and No. 7. Never the less, PD subject No. 1 did not show any correlation between LF/HF and AC.

Long term care level of PD subjects No. 4 and No. 7 were evaluated as level 1, but long term care level of PD subject No. 1 was level 2. Two PD subjects No. 2 and No. 8 showed negative correlations between LF/HF and AC during waking time. Their long term care level was 4 severe, and engaged activity was not good. PD subject No. 3, her long term care need level was level 4, showed wandering around. Her increased AC was caused by the wandering, therefore it was not considered a factor influencing a negative correlation among the LF/HF and AC.

Considering all the data, "motivated activity, engaged activity, communication ability, no wandering around, and no night-time awakening, indicated less need for care”, influencing the correlation between LF/HF and AC, $\mathrm{HF}$ and AC. With these data, it was considered that it was necessary to investigate the relationship between autonomic nervous activity and activity of patients with dementia and their care needs level.

As shown in Table 3, fifteen out of 16 HPs and 4 out of 9 PDs showed significantly higher LF/HF when awake than asleep. It was considered that limited physical activities influenced the result because PDs spent long hours lying in bed or watching TV while they were awake. One PD showing significantly higher HF while awake spent more time confined to bed. He also took naps for 20 minutes and woke up once in the middle of night. This showed that HF was higher during waking hours than sleeping due to habits of lying in bed and taking naps. The researchers found that the HF was higher during sleep than during bed rest and nap times during the day.

As shown in Table 1, since 2 out of these 3 PDs became psychologically stable by taking regular strength tranquilizers or minor tranquilizers, positive correlations between LF/HF and AC was observed. Two PDs indicating negative correlations between LF/HF and AC during awakening needed to be highly cared for because their physical activities were limited. The PD with positive correlation between LF/HF and AC, was explained by the taking of antipsychotic drugs after lunch. These medications affected her behavior.

In the PD subject No.5, using data from Figure 4, positive correlation between LF/HF and AC, and negative correlation between HF and AC were evident only in the PD during sleeping time. This PD length of sleep was 9.5 hours without mid-arousal. Also considered from data shown in Table 1, this PD took Etizolam 0.5 mg, and Brotizolam $0.25 \mathrm{mg}$ at 18:30. Etizolam effect on heart rate has been reported to be almost unprecedented (heart rate values remained within normal ranges) [32]. In addition, there is a report on the effect of decreased heart rate when Brotizolamis used [33]. However, there were no problems with heart rate exhibited. In healthy people, it was reported that a decrease in the heart rate was observed [34] from the time of awaking to the time of sleeping. However, there was no observed decrease in the heart rate in this PD. It is because there is no change in the amount of physical activity. It was shown that the PD had body movements during sleep, positive correlation LF/HF and AC, negative correlation to the HF and AC were observed.

Similarly, in regard to the PD who was without correlation during awakening, her behavior was affected by the antipsychotic medications taken after dinner. In addition, PDs were using tranquilizers in order to restrain BPSD, as the tranquilizers effect was to suppress sympathetic nervous activities [35] [36]. Since they were not fully capable of moving their bodies and were taking medication, sympathetic nervous activities were considered to be restrained.

As indicated in Table 2, the data showed that four PDs did not show positive correlations between LF/HF and AC during waking hours, while 2 PDs revealed a negative correlation. Nevertheless, from the analysis of their behavioral observations and HRV, it was confirmed that their LF/HF increased while undergoing rehabilitation or communicating with others. Thus, these results suggested that activities in the institution affected autonomic 
nervous activity in subjects although they had limited physical activities.

As shown in Table 4, combined results of behavioral observation, actigrapy and HRV analyses suggested that PDs showed positive correlations between LF/HF and AC in a wakeful state. Compared to those who showed no positive correlation, they did not require much nursing care.

PD subject No. 3 showed the longest arousal time during sleep. This resulted from her TV viewing from 23:00 until 1:30 in the morning. There was no significant correlation between LF/HF and AC, and HF and AC (Table 4), Table 6 indicating that there was no physical activity during TV watching.

Six PDs did not show a positive correlation with the LF/HF and AC during waking time. Their situation was that they were all sitting or had bed rest at that time. They had no activities such as watching TV or reading newspapers. Their physical and mental activities were small and therefore unremarkable, so that their heart rates did not increase. LF/HF did not show high values, which indicated that there was no mental activity, such as watching TV or reading newspapers.

As shown in Table 3, fifteen out of 16 HPs indicated significantly higher values of LF/HF when awake than when asleep. One HP, however, showed no significant difference in the mean value of LF/HF between them. Although she didn't leave her bed, she woke up twice in the middle of night. The value of LF/HF in a wakeful state only increased shortly after she got up. She was an office worker and rarely did exercises.

\section{Limitations of the Study}

The researchers had 23 PDs as subjects, however, 15 PDs discontinued their participation; some removed their actigraphs and electrodes from the Holter Electrocardiographic Monitor. Because the target subjects were PDs, some failed to maintain the use of the actigraph, and had to drop out. Furthermore, because older persons often suffer from diseases that affect the autonomic nervous system such as diabetes mellitus or cardiac diseases, they were not included. In addition, healthy elderly persons were difficult to recruit considering the required activities of the research protocol. In both PD and normal patient cases, there were more data for women than men, which made it difficult to examine the influence of gender.

Although zero crossing modes were used to measure the amount of activities with the actigraph, it might be necessary to measure a proportional integral mode [37]. In setting the actigraph to zero crossing mode (the method used to evaluate the quality of sleep), the threshold AC count was kept low, which calculated the number of slight movements that patients made in their sleep to judge the quality and time of sleep onset and awakening. As a result, it was difficult to measure the patients' activity during the daytime. While this study only reported data from 9 PDs it was realized that continued research on the characteristic of autonomic nervous responses be encouraged in order to obtain accumulated data as evidence.

\section{Conclusion}

The characteristics of autonomic nervous activity of institutionalized PDs and HPs were as follows: the mean value of LF/HF in a wakeful state was significantly lower for PDs than HPs. Combined results of behavioral observation, actigrapy and HRV analyses suggested that PDs showed positive correlations between LF/HF and AC in a wakeful state. Compared to those who showed no positive correlation, they did not require much nursing care. Furthermore, those PDs were actively involved in activities including watching TV or reading newspapers and also maintained communication capabilities. Findings suggested that there is a possibility that not only physical activities but also cognitive behavioral functions such as communication capabilities and assertiveness affect the sympathetic nervous activities of persons living with Alzheimer's disease.

\section{Acknowledgements}

We would like to express our deep gratitude to the subjects/participants of this study, members of Professor Tanioka's laboratory. In particular, we wish to thank the following clinicians for their participation in this study: Dr. Haruo Kobayashi, VM; PhD; Dr. Mihoko Nakanii, RN, PhD (Kawasaki University of Medical Welfare); Dr. Kazushi Mifune, MD; PhD, Dr. Hiroshi Ogasawara, MD; PhD, and Ms. Keiko Nagao, RN, Head Nurse (San Ai Kai). Also, to all the registered nurses and certified care workers at the Fukujyusou, for their understanding and assistance in this study. 


\section{References}

[1] Japan: Ministry of Health Labour and Welfare (2015) About the Current State of Nursing Care Facilities. http://www.mhlw.go.jp/shingi/2006/09/dl/s0927-8d.pdf (In Japanese)

[2] Japan: Ministry of Health Labour and Welfare (2015) Long-Term Care Insurance Facility. http://www.mhlw.go.jp/stf/shingi/2r9852000001dzdp-att/2r9852000001dzhk.pdf (In Japanese)

[3] Japan: Ministry of Health Labour and Welfare (2013) Research Project on the Home Return Support of a Long-Term Care Health Facility (Preliminary Version).

http://www.mhlw.go.jp/file/05-Shingikai-12601000-Seisakutoukatsukan-Sanjikanshitsu_Shakaihoshoutantou/0000061 551.pdf (In Japanese)

[4] Hattori, M. (2011) The Stress on the Part of Care Takers at the Aged Society. Stress Science Research, 26, 1-7. http://dx.doi.org/10.5058/stresskagakukenkyu.26.1

[5] Lee, M.S., Cho, B.J., Min, G.H. and Kim, S.R. (2015) Effects of Therapeutic Recreation on the Brain Quotient in the Elderly Dementia Patients. Journal of Physical Therapy Science, 27, 1909-1911. http://dx.doi.org/10.1589/jpts.27.1909

[6] Heyn, P., Abreu, B.C. and Ottenbacher, K.J. (2004) The Effects of Exercise Training on Elderly Persons with Cognitive Impairment and Dementia: A Meta-Analysis. Physical Medicine and Rehabilitation, 85, 1694-1704.

http://dx.doi.org/10.1016/j.apmr.2004.03.019

[7] Kolanowski, A., Fick, D.M. and Buettner, L. (2009) Recreational Activities to Reduce Behavioural Symptoms in Dementia. Geriatrics Aging, 12, 37-42.

[8] Treiber, K.A., Carlson, M.C., Corcoran, C., Norton, M.C., Breitner, J.C., Piercy, K.W., Deberard, M.S., Stein, D., Foley, B., Welsh-Bohmer, K.A., Frye, A., Lyketsos, C.G. and Tschanz, J.T. (2011) Cognitive Stimulation and Cognitive and Functional Decline in Alzheimer's Disease: The Cache County Dementia Progression Study. The Journals of Gerontology, Series B: Psychological Sciences and Social Sciences, 66, 416-425. http://dx.doi.org/10.1093/geronb/gbr023

[9] Heser, K., Wagner, M., Wiese, B., Prokein, J., Ernst, A., König, H.H., Brettschneider, C., Riedel-Heller, S.G., Luppa, M., Weyerer, S., Eifflaender-Gorfer, S., Bickel, H., Mösch, E., Pentzek, M., Fuchs, A., Maier, W., Scherer, M., Eisele, M. and AqeCoDe Study Group (2014) Associations between Dementia Outcomes and Depressive Symptoms, Leisure Activities, and Social Support. Dementia and Geriatric Cognitive Disorders Extra, 4, 481-493. http://dx.doi.org/10.1159/000368189

[10] Hirai, S. (2001) Distinction between Dementia and Memory Decline. Japan Medical Association Journal, 44, $274-278$.

[11] Tarawneh, R. and Holtzman, D.M. (2012) The Clinical Problem of Symptomatic Alzheimer Disease and Mild Cognitive Impairment. Cold Spring Harbor Perspectives in Medicine, 2, a006148. http://dx.doi.org/10.1101/cshperspect.a006148

[12] Mori, T. and Ueno, S. (2011) Support Provided to Dementia Patients by Caregivers and the Community. Journal of the Japan Medical Association, 139, 2149-2151.

[13] Hishikawa, N., Takahashi, Y., Amakusa, Y., Tanno, Y., Tuji, Y., Niwa, H., Murakami, N. and Krishna, U.K. (2012) Effects of Turmeric on Alzheimer's Disease with Behavioral and Psychological Symptoms of Dementia. AYU, 33, 499-504. http://dx.doi.org/10.4103/0974-8520.110524

[14] Wade, A.G., Farmer, M., Harari, G., Fund, N., Laudon, M., Nir, T., Frydman-Marom, A. and Zisapel, N. (2014) Add-On Prolonged-Release Melatonin for Cognitive Function and Sleep in Mild to Moderate Alzheimer’s Disease: A 6-Month, Randomized, Placebo-Controlled, Multicenter Trial. Clinical Interventions in Aging, 9, 947-961.

[15] European Delirium Association and American Delirium Society (2014) The DSM-5 Criteria, Level of Arousal and Delirium Diagnosis: Inclusiveness Is Safer. BMC Medicine, 12, 141. http://dx.doi.org/10.1186/s12916-014-0141-2

[16] Sakamoto, M., Ando, H. and Tsutou, A. (2013) Comparing the Effects of Different Individualized Music Interventions for Elderly Individuals with Severe Dementia. International Psychogeriatrics, 25, 775-784. http://dx.doi.org/10.1017/S1041610212002256

[17] Okada, K., Kurita, A., Takase, B., Otsuka, T., Kodani, E., Kusama, Y., Atarashi, H. and Mizuno, K. (2009) Effects of Music Therapy on Autonomic Nervous System Activity, Incidence of Heart Failure Events, and Plasma Cytokine and Catecholamine Levels in Elderly Patients with Cerebrovascular Disease and Dementia. International Heart Journal, 50, 95-110. http://dx.doi.org/10.1536/ihj.50.95

[18] Yang, M.H., Lin, L.C., Wu, S.C., Chiu, J.H., Wang, P.N. and Lin, J.G. (2015) Comparison of the Efficacy of Aroma-Acupressure and Aromatherapy for the Treatment of Dementia-Associated Agitation. BMC Complement \& Alternative Medicine, 29, 93. http://dx.doi.org/10.1186/s12906-015-0612-9

[19] Sato, M., Yasuhara, Y., Tanioka, T., Iwasa, Y., Miyake, M., Kobayashi, H., Locsin, R., Kinoshita, S., Masuda, M. and Shimizu, H. (2013) The Relationship between Sleep Condition and Autonomic Nervous Function in Women in Their 
70s with Type 2 Diabetes Mellitus. Health, 5, 1875-1883. http://dx.doi.org/10.4236/health.2013.511253

[20] Sato, M., Yasuhara, Y., Tanioka, T., Iwasa, Y., Yasui, T., Miyake, M., Kobayashi, H., Waraporn, K. and Locsin, R. (2013) Changes before and after Improvement of Subjective Sleep State of a Man Diagnosed with Pre-Diabetes and Sleep Disorder. Health, 5, 504-511. http://dx.doi.org/10.4236/health.2013.53A069

[21] Sato, M., Yasuhara, Y., Tanioka, T., Iwasa, Y., Miyake, M., Yasui, T., Tomotake, M., Kobayashi, H. and Locsin, R. (2014) Measuring Quality of Sleep and Autonomic Nervous Function in Healthy Japanese Women. Neuropsychiatric Disease and Treatment, 10, 89-96.

[22] Vanoli, E., Adamson, P.B., Ba-Lin, Pinna, G.D., Lazzara, R. and Orr, W.C. (1995) Heart Rate Variability during Specific Sleep Stages: A Comparison of Healthy Subjects with Patients after Myocardial Infarction. Circulation, 91, 19181922. http://dx.doi.org/10.1161/01.CIR.91.7.1918

[23] Hishikawa, N., Takahashi, Y., Amakusa, Y., Tanno, Y., Tuji, Y., Niwa, H., Murakami, N. and Krishna, U.K. (2012) Effects of Turmeric on Alzheimer's Disease with Behavioral and Psychological Symptoms of Dementia. AYU, 33, 499-504. http://dx.doi.org/10.4103/0974-8520.110524

[24] Imai, Y. and Hasegawa, K. (1994) The Revised Hasegawa’s Dementia Scale (HDS-R)—Evaluation of Its Usefulness Screening Test for Dementia. Hong Kong Journal of Psychiatry, 4, 20-24.

[25] Japan: Ministry of Health Labour and Welfare (2002) The Long-Term Care Insurance System. http://www.mhlw.go.jp/english/topics/elderly/care/2.html

[26] Chung, G.S., Choi, B.H., Jeong, D.U. and Park, K.S. (2007) Noninvasive Heart Rate Variability Analysis Using Loadcell-Installed Bed during Sleep. Proceedings of the 29th Annual International Conference of the IEEE EMBS, Lyon, 22-26 August 2007, 2357-2360.

[27] Sandroff, B.M., Motl, R.W. and Suh, Y. (2012) Accelerometer Output and Its Association with Energy Expenditure in Persons with Multiple Sclerosis. Journal of Rehabilitation Research \& Development, 49, 467-476. http://dx.doi.org/10.1682/JRRD.2011.03.0063

[28] Hjorth, M.F., Chaput, J.P., Michaelsen, K., Astrup, A., Tetens, I. and Sjödin, A. (2013) Seasonal Variation in Objectively Measured Physical Activity, Sedentary Time, Cardio-Respiratory Fitness and Sleep Duration among 8-11 YearOld Danish Children: A Repeated-Measures Study. BMC Public Health, 13, 808. http://dx.doi.org/10.1186/1471-2458-13-808

[29] Cole, R.J., Kripke, D.F., Gruen, W., Mullaney, D.J. and Gillin, J.C. (1992) Automatic Sleep/Wake Identification from Wrist Activity. Sleep, 15, 461-469.

[30] Murakami, S., Yamanaka, T., Kubo, Y., Wada, T., Yano, S., Nishimura, Y., Shinagawa, M., Matsubayashi, K., Otsuka, K., Ohkawa, S. and Kawata, H. (2002) Heart Rate Variability Analysis and Neurobehavioral Function in Community-Dwelling Older People Aged 75 or Older. The Journal of Japan Geriatric Society, 39, 520-526. (In Japanese) http://dx.doi.org/10.3143/geriatrics.39.520

[31] Zhao, R., Li, D., Zuo, P., Bai, R., Zhou, Q., Fan, J., Li, C., Wang, L. and Yang, X. (2015) Influences of Age, Gender, and Circadian Rhythm on Deceleration Capacity in Subjects without Evident Heart Diseases. Annals of Noninvasive Electrocardiology, 20, 158-166. http://dx.doi.org/10.1111/anec.12189

[32] De Candia, M.P., Di Sciascio, G., Durbano, F., Mencacci, C., Rubiera, M., Aguglia, E., Garavini, A., Bersani, G., Di Sotto, A., Placidi, G. and Cesana, B.M. (2009) Effects of Treatment with Etizolam $0.5 \mathrm{mg}$ BID on Cognitive Performance: A 3-Week, Multicenter, Randomized, Double-Blind, Placebo-Controlled, Two-Treatment, Three-Period, Noninferiority Crossover Study in Patients with Anxiety Disorder. Clinical Therapeutics, 31, 2851-2859. http://dx.doi.org/10.1016/j.clinthera.2009.12.010

[33] Kushiku, K., Morishita, H., Furukawa, T., Kitagawa, H., Ueno, K., Kitagawa, H. and Kohei, H. (1986) Effects of Brotizolam on Cardiovascular Functions and Autonomic Nervous System. Arzneimittelforschung, 36, 552-559.

[34] Saito, K., Kondo, C., Nishioka, Y., Tamura, Y. and Mori, H. (1983) Study of the Sinus Function in Active Elderly Subjects: Evaluation of Diurnal Variation of Heart Rate by Ambulatory Electrocardiography. Heart, 15, 307-315. (In Japanese)

[35] Fujibayashi, M., Matsumoto, T., Kishida, I., Kimura, T., Ishii, C., Ishii, N. and Moritani, T. (2009) Autonomic Nervous System Activity and Psychiatric Severity in Schizophrenia. Psychiatry and Clinical Neurosciences, 63, 538-545. http://dx.doi.org/10.1111/j.1440-1819.2009.01983.x

[36] Nunn, N., Feetham, C.H., Martin, J., Barrett-Jolley, R. and Plagge, A. (2013) Elevated Blood Pressure, Heart Rate and Body Temperature in Mice Lacking the XL $\alpha$ s Protein of the Gnas Locus Is Due to Increased Sympathetic Tone. Experimental Physiology, 98, 1432-1445. http://dx.doi.org/10.1113/expphysiol.2013.073064

[37] Blackwell, T., Redline, S., Ancoli-Israel, S., Schneider, J.L., Surovec, S., Johnson, N.L., Cauley, J.A., Stone, K.L. and Study of Osteoporotic Fractures Research Group (2008) Comparison of Sleep Parameters from Actigraphy and Polysomnography in Older Women: The SOF Study. SLEEP, 31, 283-291. 